\title{
Effectivity of ACTIVE Model in Practice Learning of Nursing Education Profession Phase at Nursing College Sukabumi
}

\author{
$1^{\text {st }}$ Irawan Danismaya \\ Nursing Department \\ Faculty of Health Science \\ University Muhammadiyah Sukabumi \\ Sukabumi, Indonesia \\ idanismaya@yahoo.co.id
}

\author{
$2^{\text {nd }}$ Ria Andriani \\ Nursing Department \\ Faculty of Health Science \\ University Muhammadiyah Sukabumi \\ Sukabumi, Indonesia
}

\begin{abstract}
Practice learning model in nursing college of Indonesia are various and depends on its each targeted alumni profile. The Nursing College in Sukabumi have implemented ACTIVE model which effectivity have been evaluated periodically. Student ability to apply of nursing process, management process, and their's feel of ecurity are measured. 99 students are chosen as respondents in a total sampling technique data gathering. The data gathering uses 3 kinds of Likert scaled questionnaire. Data analysis is purposed to find the median and frequency distribution. Nursing diagnosis formulation phase has the highest value that is $81.82 \%$ and the highest average value in nursing implementation phase is 3.16. The actuating phase has the highest value that is $40.40 \%$ dan the highest average value in communicating phase is 3.08. The majority of student's feel of Security belongs to slight anxienty category with value $\mathbf{8 3 . 8 4 \%} \%$. The conclusion is that the student's competency level in implementing nursing process is categorized in new beginner to proficient level. The student's skill in implementing management process is categorized in new beginner to competent. Their's fee of security while in practice learning progress is categorized in slight anxienty.
\end{abstract}

Keywords-ACTIVE Model, Learning, Nursing Education

\section{INTRODUCTION}

Indonesian nursing higher education refers to Indonesian Nursing Law number 38 of 2014, was divided into 2 stages namely Vocational Education and Professional Education. Bachelor of Nursing degree is a level education programme aimed to get a professional nurses. The Nursing education program has two learning stages namely the Academic Stage and the Professional Stage as an inseparable whole. Nursing students are gradually directed to understand the theories and concepts in the classroom / laboratory and then apply them in the field of practice. The ultimate goal of the Nursing Education program is to quote from Association of Indonesian Nurse Education Center/AINEC (2015) that is trying to reach the graduate profile as Manager and Leader, Coomunicator, Educator and Helath Promoter, Researcher and Care Provider [1]. A proven learning model must always be applied to ensure that the objectives of each learning phase can be achieved. Discussions with managers of nurses education institutions in West Java found many differences in the practical learning model of the professional stage. Although the 2015 Curriculum from AINEC has been used as a guideline by its members. Another challenge is how the concept of integrated learning can be applied.

Often students learn to apply the Nursing Process (NP) stage in a situation where the practice land is in management trouble. Or vice versa when students learn to apply the Nursing Management Process (NM) stage, but nursing care to individual patients is ignored. Students must be convinced to be able to understand that NP and NM are inseparable and must be done simultaneously. The learning process of the Professional Stage also often burdens students with writing and learning concepts. Though ideally it should lead students to learn to apply concepts / theories that have been learned at the Academic Stage. This will be a problem if graduates of the Nursing Education program only have high cognitive abilities but are weak in applying a concept. The Indonesian Nurses Association (INA) clearly confirms that the Academic Phase is aimed at mastering and developing nursing knowledge, while the Professional Stage is carried out so that students are able to work according to the standards of nursing professional practice. (www.inna-ppni.or.id, accessed July 2017) [2].

The basic pattern of Preseptorship in learning the practice of the Professional Stage. Students learn directly from nurses how to treat patients, perform procedures and behave ethically while carrying out nursing care. Clinical practice is only carried out in practice areas that consistently apply NP to every patient that is supported by good unit management. Students are directed to apply the steps of the NM Phase and NP Phase to achieve 5 profiles of Nursing Education graduates.

Indonesian Nurse Education consists of 2 stages of a learning program namely the Academic Stage and the Professional Stage. Academic education is directed at the mastery and development of branches of Science and Technology (Article 15 of Indonesian Law No. 12 of 2012) [3]. The professional stage is mentioned as an educational program after an undergraduate program aimed at preparing students to be able to work in a job that 
requires special expertise requirements. Graduates must be able to provide care in accordance with the objective needs of the client, and conduct supervision of nursing practice conducted by novice professional nurses. The Nursing Education Program at The Nursing College in Sukabumi is based on higher education curriculum standards from the Indonesian Ministry of Research \& Higher Education and also of the AINEC.

Nursing Process (NP) is a scientific thinking pattern that must be carried out by every nurse and will only be effective if it is applied in a work environment that implements the Nursing Management (NM) process properly. NP and NM are unidirectional, inseparable and purposeful processes, namely the achievement of patient satisfaction. Professional practice learning at The Nursing College in Sukabumi facilitates the application of PK and MK in an integrated manner and is called the ACTIVE model (Danismaya, 2014) [4]. Learning activities in the "ACTIVE" model are a series of systematic, gradual and continuous learning activities consisting of Assessment (A), Communicating (C), Team of Care Celivery (T), Individual case management (I), Verbal response (V) and finally is Evaluation (E).

There are 3 aspects assessed related to the implementation of the Nursing Process, consist of clinical perfomance, verbal response and documentation. Whereas the ability to apply the Management Process is assessed from the Planning Process, Leadership Skill and documentation skills. This integrated learning model framework is formulated in steps of clinical practice activities called the ACTIVE model. A preliminary study of the knowledge of the 2015/2016 Academic Year Professional Stage about the theory of 5 Stage NP more than $80 \%$ included in both categories [5]. But the skill level of applying the stages of the process identified in the category is quite bad. 8 people claimed to be confused when they had to conduct an assessment in a busy situation because of the large number of patients. They also find it difficult to choose the aspects of focus that must be studied. The skill to record continuously 24-hour care activities is very weak. This condition is relevant to the results of Elta's research (2016) that there is a relationship between the Academic Grade Accumulation Achievement Index and the ability to apply the Nursing Process at the Professional Stage.[6]

Regarding learning in implementing the Constitutional Court process, 12 people stated that they did not know how to start the management process in one place which had become a practice area many times. They also claimed to be ashamed and felt insecure about them when they had to communicate with their seniors. The learning methods of management practice at the West Java Nursing University were identified as being divided into 2 approaches. Academic management of 7 universities states that it applies a comprehensive management practice learning process based on the vision of health service institutions, while 3 other universities apply a problem-based management learning learning model [7], including in The Nursing College in Sukabumi. Doubts about the effectiveness of the model often become a topic of discussion among managers of the Nursing study program at The Nursing College in Sukabumi. Evaluation of program targets is always done periodically at the end of every education program.

Based on the application of the ACTIVE learning model that has been carried out at the Professional Stage of the Nurse Education Program at The Nursing College in Sukabumi, a problem statement is prepared namely; "How is the effectiveness of the ACTIVE model in the Practice of Nursing Education Professional Stage at The Nursing College in Sukabumi? " The general objective in this study was to know the effectiveness of the application of the ACTIVE model in the practical learning of Nurse Education Professional Stage at The Nursing College in Sukabumi. While the specific objectives in this study are ; to identification of the skill level to apply of Nursing Process, to apply of Nursing Management and the level of security during the practical learning.

\section{RESEARCH METHODS}

Practical Learning Professional Stage is an activity carried out by students after successfully passing a series of learning in class and laboratory at the academic stage. 3 variables measured were: the skills to apply the Nursing Process, apply the Management Process and a sense of security during practice. The measured competence refers to the competence of the Beginner level (Advanced beginner) which is characterized by achieving documented repetitive behavior patterns using teaching standards and patient care plans, as well as referring to the needs of the patient and his family. A sense of security is a psychological experience that is felt during learning in practice. The study was conducted from February to July 2017 at The Nursing College in Sukabumi Campus. The population is all students in the 2016/2017 academic year who are active. Total Sampling technique was used so that 99 students were sampled. Data collection is done after the judicial process is conducted by the study program manager. Using 3 instruments that contain statements asking for answers to respondents on a Likert scale from 1 to 5 . Safety is measured using instruments from HARS. Data analysis is performed to find the frequency distribution and the mean value.

\section{RESULT AND DISCUSSION}

The number Respondent were 99 student nursing that consisting of $58.59 \%$ men and $41.41 \%$ women. Students' skills in conducting nursing studies are greatest at the competent level. This means that there are 78 students able to collect and select data relevant to the patient's condition without assistance. There was one person who was noted to be able to help and teach his juniors. Whereas students' skills in formulating Nursing Diagnosis were the most distributed in the competent level of 81 people. This means that the student concerned is able to categorize, analyze and formulate conclusions precisely without being helped. [8] There are only 2 people in the professional category, which is able to teach others well. The activities of formulating a nursing plan are prioritizing problems, formulating goals and formulating 
intervention plans. An increase in the number of students included in the Novice / Novice category is 26 people compared to the previous 2 stages, meaning students need to be accompanied and dependent on their seniors. Meanwhile, when entering the implementation phase, there was also a significant increase in the Proficient group of 26 people. This means that procedurally the student is able to carry out well the related procedures and be able to help his colleague when performing the procedure. There were 73 students included in the

TABEL 1. DISTRIBUTION OF FREQUENCY FOR THE ABILITY OF STUDENT TO APPLY NURSING PROSES ACTIVITY.

\begin{tabular}{|l|l|l|l|l|l|}
\hline Level & Asssesment & Diagnosis & Planning & Implementation & Evaluation \\
\hline Novice & 5.5 & 6.06 & 26.26 & 2.02 & 6.06 \\
\hline Advance Beginner & 15.15 & 10.10 & 29.29 & 6.06 & 18.18 \\
\hline Competent & 78.79 & 81.82 & 44.44 & 65.66 & 73.74 \\
\hline Proficient & 1.01 & 2.02 & 0.0 & 26.26 & 2.02 \\
\hline Expert & 0.0 & 0.0 & 0.0 & 0.0 & 0.0 \\
\hline The Average & 2.76 & 2.79 & 2.18 & 3.16 & 2.72 \\
\hline
\end{tabular}

The measurement of students' skills in applying the management process is based on 4 stages of activity. The highest skill distribution in the Planning phase is at the advance beginner level of 56 people. The planning process is a student's activity in identifying management problems that are happening, and then developing data so that they can be formulated into problems and plan solutions. While the distribution of student skills in advocating and communicating the results of most planning is at the competent level and seen 5 people included in the expert category. This means that students are able to understand well the whole process and how to communicate and work in teams in an organization. At the implementation stage of the assignment all students who are not included in the category need guidance or depend
Competent level at the evaluation stage, although 6 of them were at the Novice level which meant that they still needed guidance / dependence on others. Then the competence with the highest average is at the implementation stage, which is 3.16 , which means that it is included in the competent to proficient category. The lowest is at the planning stage is 2.18 which is in the category of New beginner to competent. Table 1 have all the result.

TABEL 2. DISTRIBUTION OF FREQUENCY FOR THE ABILITY OF STUDENT TO APPLY MANAGEMENT PROCESS ACTIVITY.

\begin{tabular}{|l|l|l|l|l|}
\hline Level & Planning & Communicating & Actuating & Evaluating \\
\hline Novice & 3.03 & 0.0 & 0.0 & 2.02 \\
\hline Advance Beginner & 56.57 & 30.30 & 29.29 & 57.57 \\
\hline Competent & 36.36 & 36.36 & 40.40 & 38.38 \\
\hline Proficient & 4.04 & 28.28 & 27.27 & 2.02 \\
\hline Expert & 0.0 & 5.05 & 3.03 & 0.0 \\
\hline The average & 2.41 & 3.08 & 3.04 & 2.40 \\
\hline
\end{tabular}

The table 3 shown that most of the students, $83.84 \%$, stated that they experienced mild anxiety during carrying out practical activities. A very reasonable condition considering the practical activities are new experiences for each student. The early exposure program, which is held in the 2nd semester of the Academic Phase, also helps students prepare mentally. [9]

TABEL 3. THE FEEL OF SECURITY WHILE PRACTICAL LEARNING

\begin{tabular}{|l|l|c|}
\hline Level & Frequensi & $\%$ \\
\hline Anxious weight & 2 & 2.02 \\
\hline Worried Medium & 14 & 14.1 \\
\hline Light anxiety & 83 & 83.8 \\
\hline Total & 99 & 100 \\
\hline
\end{tabular}

on others. All levels are distributed evenly at other levels. 3 people entered the expert category. This means that the attitude of motivating yourself and work motivation can be applied well by students. The biggest distribution of management evaluation stage is at the level of the beginner advance according to the level of competence that should be possessed by students. 2 people are capable of proficient but none are categorized as experts. Skills in the Planning and Evaluation stages are seen at the level of the advance beginner to competent. While the students' skills in the communication and implementation stages belong to the competent category to the professional level. All the information shown in table 2. 
[5] The Nursing College S1 Study Program in Sukabumi. (2016). Recapitulation of 2007-2011 grades. Sukabumi, The Nursing College in Sukabumi.

[6] Elta, Annisa (2016). The relationship of the Cumulative Achievement index with the ability to apply the Nursing Process. Thesis, S1 Nursing Study Program, The Nursing College in Sukabumi

[7] http://aipni-ainec.org/bookofabstract-rta20aipni202019/

[8] Jackson \& Hansten. (2015). A Handbook for professional Practice Fourth Edition. Canada, Jones \& Bartlett publisher.

[9] Perry, Potter. (2014). Fundamental Nursing concepts, processes and practices. Jakarta, EGC. 